\title{
Visual Media Discourse Analysis of John Howard's 2007 "Last Road Trip” Campaign
}

\author{
I N Rodliyah \\ Faculty of Cultural Studies, Universitas Brawijaya
}

\{iis.rodliyah@ub.ac.id\}

\begin{abstract}
This article discusses a relationship between politics and media as shown by an in-depth feature published on Saturday or weekend edition of The Sydney Morning Herald newspaper on November $10^{\text {th }}, 2007[1]$. This edition is worth analyzing because the feature that was written by a senior reporter, Michael Gawenda, marked the unpopularity of the $25^{\text {th }}$ Australian Prime Minister, John Howard, in his forthcoming election round. The report was accompanied by two sets of photographs showing snap shots of the incumbent Prime Minister that seemed to construct his negative images. This paper, thus, presents the results of a critical analysis on the photographs based on Fairclough's model for CDA which involved three interrelated processes of analysis: (1) description, (2) interpretation and (3) explanation of three interrelated dimensions of discourse[2].
\end{abstract}

Keywords: Discourse Analysis, Visual Media and Politics, The Sydney Morning Herald, General Election

\section{INTRODUCTION}

Media texts on newspaper are probably one of the most real-life discourses since they address and present daily situations and affairs that really occur in communities. In other words media texts offer a realistic portrayal of the world[3]. In portraying the world, a media may use either verbal texts and/or visual texts; and when being observed closely, the overall messages of a piece of news is not just written but, according to Kress and Leeuwen, is 'designed' and multimodally articulated[4]. There are also claims mentioning that both verbal and visual texts may be used to express the same meanings or to complement and extend each other, or even clash or contradict [4]. Therefore, it is possible to have a newspaper's article to articulate messages more through visual texts rather than the verbal ones.

Regarding the use of verbal and visual text in newspaper, Saturday or weekend edition of The Sydney Morning Herald newspaper serves as a good example of multimodality practices of a discourse. One of very good examples can be found on its weekend edition published on November $10^{\text {th }}, 2007$. This edition published an in-depth feature entitled "The Last Road Trip" which was reported by a senior reporter, Michael Gawenda, who was joining John Howard's (abbreviated as $\mathrm{JH}$ ) campaign trip. In the feature, the newspaper presented the readers with two sets of selected photographs taken during the campaign trip. The first set of photographs was arranged in a "standard way" that is usually used in newspaper's layout. However, the second set of photographs was presented in a special layout showing snap shots of the incumbent Australian Prime Minister arranged as a collage or in a scrapbook looks. Therefore, it is 
interesting to analyze the role of both the photographs and the photograph layout designs in constructing meanings and in influencing the readers of the feature or report.

\section{RESEARCH METHOD}

This research is a qualitative one attempting to present the results of a critical analysis on the two sets of photographs accompanying an article entitled "The Last Road Trip" found on the Saturday or weekend edition of The Sydney Morning Herald newspaper that was published on November 10, 2007. The analysis was conducted based on Fairclough's model for CDA as quoted in [2] which involved three interrelated processes of analysis: (1) description, (2) interpretation and (3) explanation of three interrelated dimensions of discourse that consist of (a) the object of analysis (in this case the photographs), (b) the processes by which the object is produced and received, and (c) the socio-historical conditions that govern these processes[2].

Considering that all photographs being analyzed focus on human objects, Dyer's theory on how the signs of human might symbolize is used as guidance[5]. The analysis can be conducted around the presentation of bodies, manner, activity, and properties and setting. In more details, this will involve the analysis of all possible relevant aspects found in the pictures like age, body, size, looks, expression, eye contact, pose, touch, setting, etc. This essay also presents a summary of the feature's content preceding the main discussion to provide insight into the general context.

\section{RESULT AND DISCUSSION}

"The Last Road Trip" feature was written based on the fourth week of JH campaign which according to Gawenda was an 'empty' one[1]. JH's efforts to get closer to people by hugging and glad-handing did not look sincere, and Gawenda also claimed that "the campaign rally was lack of spontaneity and debate and political speeches and humor and anything approaching real conversation - and a real confrontation - between those who want power and those who will decide who wins it[1]." This feature also reflects the senior reporter's disappointment to both the campaign trip and the content of the trip.

Having been published under the News Review of Saturday edition, this feature must have been prepared carefully since the editor had more time for editing and choosing the best photographs representing the content of the feature if compared to the daily editions. Observing the photographs closely, we can tell that they have been reasonably selected and designed to support Gawenda's opinion.

\subsection{Discussion on the first set of photographs}

The photographs put on the first set were chosen to illustrate and to tell more stories representing the lead of the news feature discussing JH's 'trend' of hugging and glad-handing people. The claim of insincerity and the uselessness found in what JH did is reflected by three photographs on the first page of the feature. The main picture, the biggest one on the left, tells everything about JH's position at the time closer to Australian general election in 2007. The picture shows JH among students in Melbourne with his two old hands trying to glad hand young boys' hands which outnumber his own hands. The other two pictures which are set beside the main picture serve to give emphasize on the vagueness behind JH's 'get-closer' efforts. 


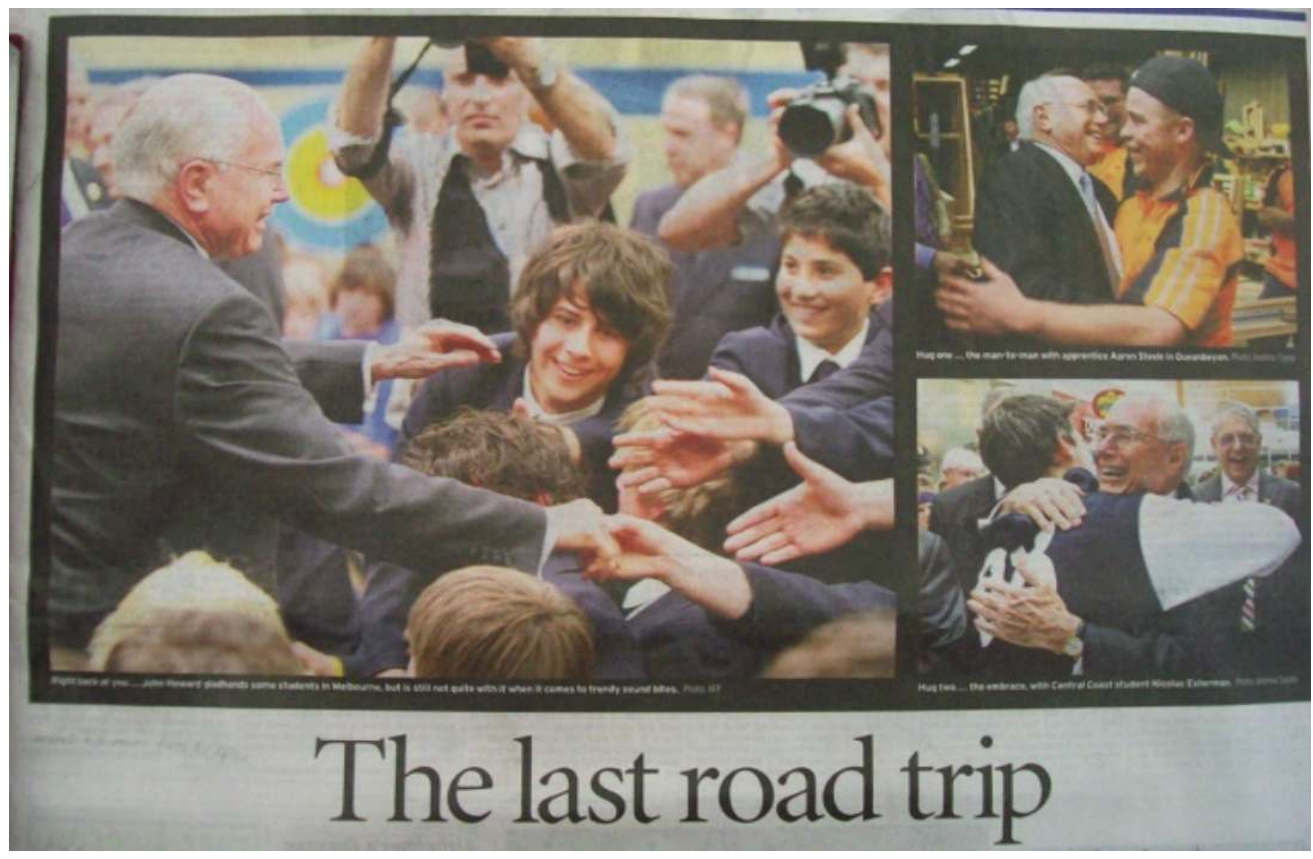

Figure 1. The first set photographs: pictures 1a, 1b, and 1c (clockwise left to right).

Picture 1a in Figure 1 is a very strong picture attempting to illustrate JH's position viewed by the young generation. The picture focuses on the lack of eye contact between the Prime Minister and a young boy who was spotted in the most salient position in the photograph i.e. in the center. Instead of looking at and smiling to $\mathrm{JH}$, the boy was looking at and smiling to another direction. This gives an impression that this young boy must have been interested in a different thing, and in a bigger context, this symbolized the ignorance of young people toward the old man and that they had their own choice to judge what is relevant to them. Another focus is JH's incapability to glad-hand all hands offered by the students that made those hands remain unattended and waited for an appropriate response from him. His failure to accommodate the school boys' hands reflects his failure in understanding and accommodating Australia's today hopes. In other words, this picture shows that he gave promises, symbolized by his hands, that he would never be able to fulfill to Australia, symbolized by the waiting hands.

The positions of $\mathrm{JH}$ and the students show another story. Their positions were not of an equal level; JH looked distant and was not part of the students. This situation was emphasized more by the age difference between them. These are portraying general opinion that it was the time for $\mathrm{JH}$ to quit his position and to pass it to the younger one because Australia should not forever rely on the past time glories but more to the current realities. The last but not least important aspect of this picture is the portrayal of two photographer journalists taking pictures of this moment deliberately. This emphasizes that what JH did is not genuine. His attempt to get closer to young people was 'made up' and not real. He did it for election campaign purposes with many people and journalists witnessing and recording the event for him to win people's heart.

The other two accompanying pictures as shown in Figure 1, pictures $1 \mathrm{~b}$ and $1 \mathrm{c}$, are positioned one above another respectively along the length of the main picture. This way, people 
would look at these two pictures simultaneously following their eyes sight moving from the main bigger picture to the smaller ones. This made the readers be able to see the contradictory on the ways $\mathrm{JH}$ did the hugs. Looking at picture $1 \mathrm{~b}$ and $1 \mathrm{c}$, one after another, people should easily tell that JH did not mean giving a sincere hug. He assigned a close but distant hug with a worker but a fully-close one with a student. These two pictures portrayed perfectly the spreading public opinion that $\mathrm{JH}$ was a bit racist and did not treat people equally.

These two pictures by themselves also carry deep meanings. In picture 1b of Figure 1, the main focus is JH and an apprentice who were hugging each other. JH's left arm perches on the apprentice back, while the apprentice's left arm has not touched him yet. This focus connoted the fact that it was JH who had the right to decide not the other one. The apprentice was allowed to hug only when JH indicated so. Therefore, the man's arm was in a waiting and doubting position and this symbolized that JH did not assign equality between him and his people. JH's pose is also deserved a strong interpretation related to his insincerity. He held back the upper part of his body, and his neck and face were very tense. It seemed that he actually refused to give the hug, he was trying not to do it, but some people were watching him and waiting to see them hugging. The other focus of the picture that strengthens the idea that the hug was politically designed is the picture of a half body of another apprentice, on the right back of the picture, who was holding his arms on his abdomen. He was not preparing himself for another hug might be executed by JH. This should show a common understanding that JH's hug had certain tendency, that he would not do it to everyone. Instead, his hugs were carefully designed and scheduled only for campaign purposes.

The last picture in Figure 1 (picture 1c) looks somehow ironic. JH was leaning his head (particularly his chin) on a student's shoulder. He looked like to find support from a younger person and laughed happily. He tried to show his 'affection' and attention to students because he understood that his rival for the election had promised better supports for students. The picture of the people behind them strengthened the ironical situation. On the left side and far behind the hugging persons, people seemed to ignore the event as it was neither impressive nor important for them. On the other side, a man standing behind them gave a big laugh. At first glance, the event seemed to deserve attention from others representing by this man. However, when looking at the picture more carefully, people could tell that the man was looking at the camera direction and his too-big laugh gave an impression that he was trying to please the Prime Minister while his focus of attention was not actually him.

\subsection{Discussion on the second set photographs}

Having been arranged and designed as a scrapbook collage, the second set of six photographs accompanying this feature tell more meanings in its own way. The pictures emphasize two important aspects being addressed by the feature which are JH's political life in general and the contents of his campaign trip. In the context of media discourse, the choice of pictures design means to assign special effects and connotations for people looking at the pictures [6]. The scrapbook layout of JH's Last Road Trip suggests an idea grounded on the cultural use of a scrapbook. People use to keep their memory of past time portrayed in their photographs in their scrapbooks. Therefore, the design of this media image told the readers that JH's last road trip was his last trip in his political life. Everything he did during the campaign trip was more suitable to be soon considered as past time events. Each of which would not promise anything for the future. This image represents a reality that JH was in his 68 and should be on his way out of prime-ministry. Being elected or not, he was almost done since he would be available for the 
prime-ministry for not more than 18 months, so eventually, he would need to keep the memory of his trip in his scrapbook.

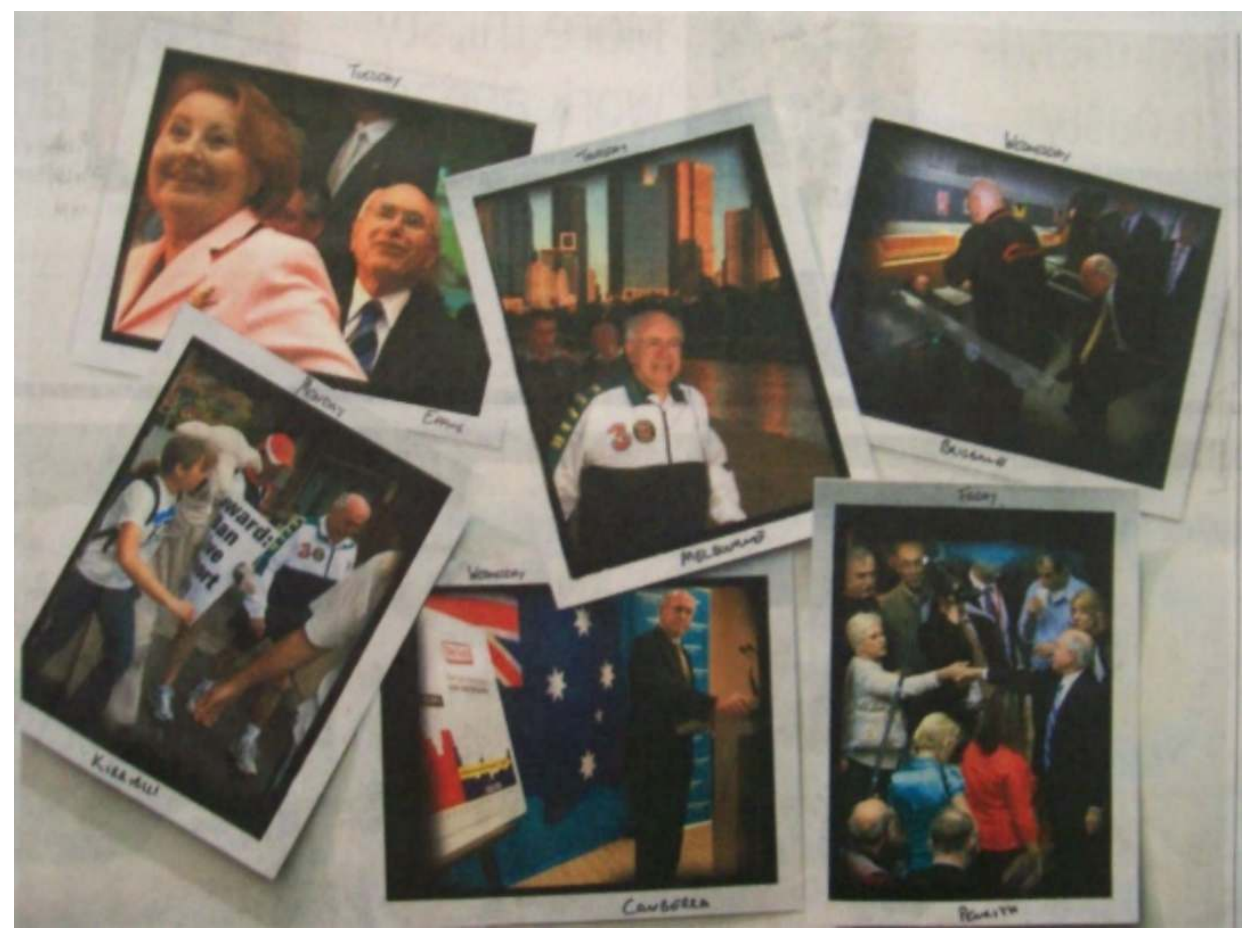

Figure. 2. The second set photographs consisting of six pictures (pictures $2 \mathrm{a}, 2 \mathrm{~b}, 2 \mathrm{c}, 2 \mathrm{~d}, 2 \mathrm{e}$, and 2f).

Another interesting feature of the second set photographs is the caption used. Here, the caption was written using hand-writing style and mentioning only the day and the location of an event in the pictures. This strategy is actually to emphasize that JH campaign trip was meaningless and unimportant; therefore, it was not necessary to provide any information directly related to the event in the pictures. This decision is relevant to a theory suggesting that the caption is used to provide a set of linguistics meanings which shape our reading and understanding of the pictures[6].

The photographs that were involved in the design also seemed to be carefully selected. The photographs are chosen to show the readers what Gawenda reported as the emptiness and the meaninglessness of the campaign trip and of what $\mathrm{JH}$ did during the trip period. In general, none of these pictures showed any impressive activities executed by JH. They show unimpressive efforts of an old man trying to convince people that he was worth electing, but all he did would only make people think the other way around. Picture 2a in Figure 3 delivers this message. 


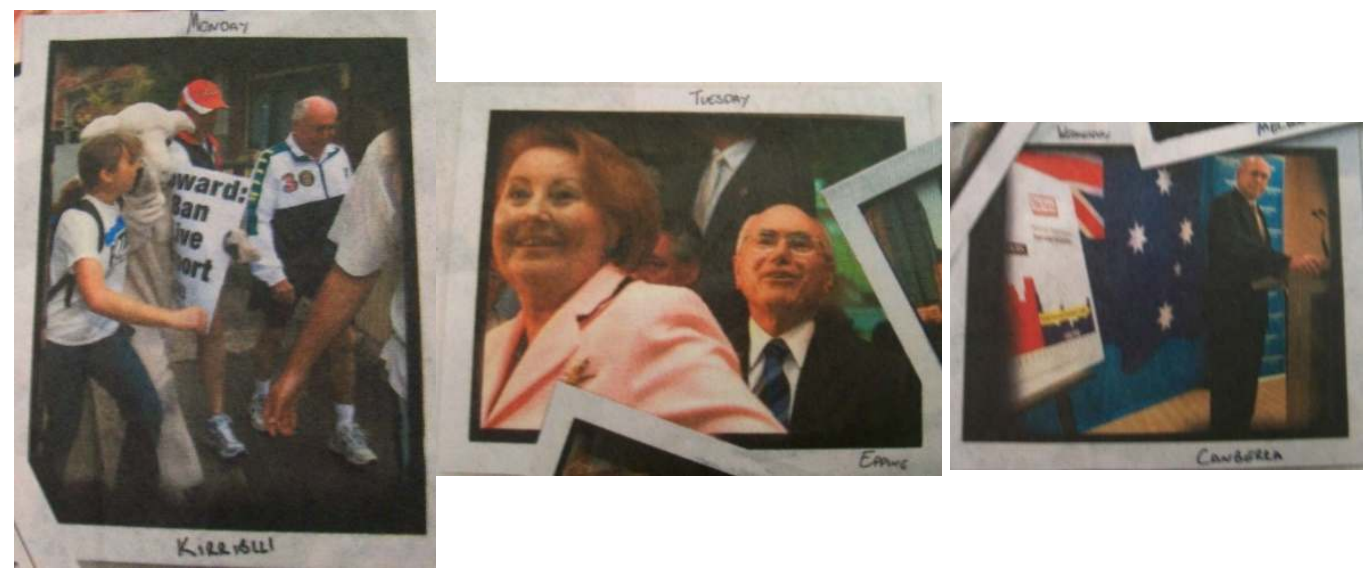

Figure. 3. Picture 2a, Picture 2b, Picture 2c (left to right).

Picture 2a in Figure 3 that was taken on Monday morning as shown by the caption shows JH who went walking while other people prepared themselves for the first working day of a week. For sure, this situation was not impressive. He seemed to do what a retired old man would do, going for a walk at the beginning of a week as if there was nothing more important to do. Whereas, everyone must have understood that a prime minister of a country as big as Australia should handle more important tasks than just walking on Monday morning. The picture also shows JH's ignorance of the real opinion and aspiration of people. Encountering a sheep girl protesting against the live-sheep export trade, JH chose to keep going on his way and left the protest unanswered. His bending his head down subjects to an interpretation that he did not confidence in defending the policy, and he might try to create an impression that arisen protest was not important.

The picture $2 \mathrm{~b}$ in Figure 3 offers a message that it was the time for $\mathrm{JH}$ to be unfollowed and not to be elected. The picture shows that even his wife was not standing behind him to support him, or beside him to cooperate with him, but she was heading towards other direction and leaving him behind. If his closest person was inconsiderably leaving him behind, other people could do the same thing even more easily. The last picture in Figure 3, picture 2c, also shows the emptiness of his campaign activity. In this picture, $\mathrm{JH}$ was standing on a podium about to give a speech. However, this picture does not portray JH as showing any spirit, energy, or enthusiasm. His straight figure and straight facial expression invited people to think that it must be a plain and dull speech, and again he was portrayed as an alone guy in this picture. 

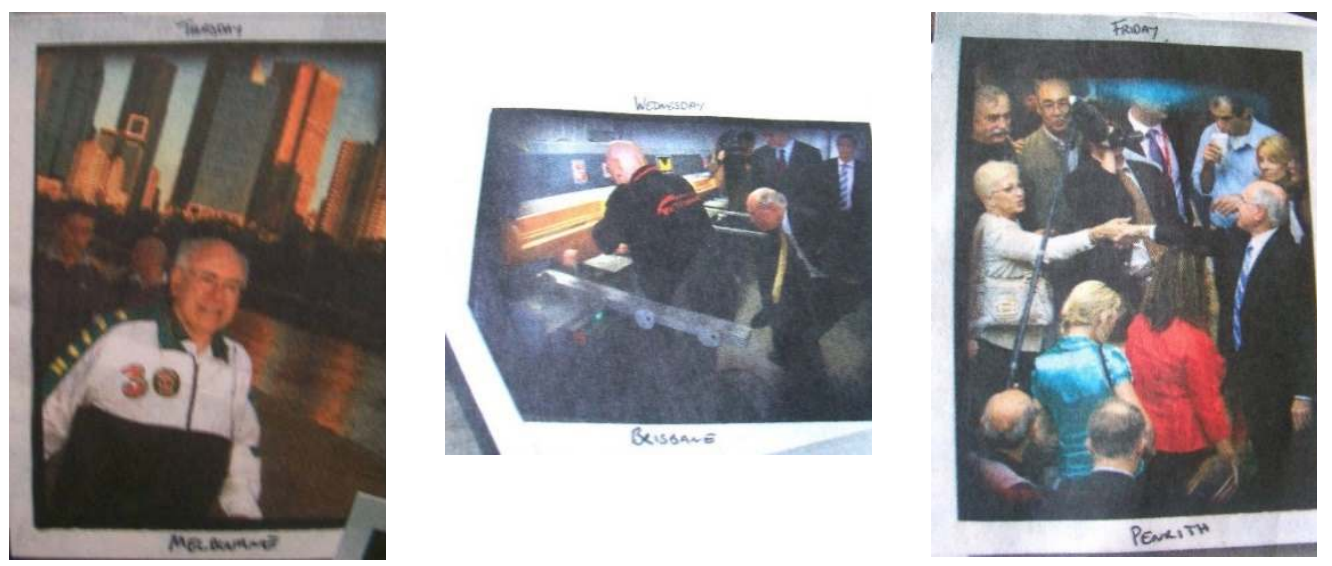

Figure. 4. Picture 2d, Picture 2e, and Picture $2 \mathrm{f}$ (left to right).

Some significant meanings are also depicted by picture $2 \mathrm{~d}$ in Figure 4 . The picture shows an old man's effort to be recognized as being fit at his age. He also tried to look trendy by practicing an 'i-pod generation' style i.e. having ear-buds on while walking. This way he tried to convince people that he was not an out of date man, and he was always able to deal with new and current life trends. However, people would easily tell that it was not the case. Considering that his walking rites was just recently, and in the campaign for election period context, people opinion on what he was doing would remain around the political context. It was a part of the campaign, so there was a possibility that it was not the real version of what he was doing on a regular basis. His tracksuit uniform was also potential to an argument. A big logo of a sponsoring telecommunication company is embedded on the upper front of his tracksuit. The argument would not arise when the suit was designed for a collective sport event joined by many people or participants. But, in this picture, it was a personal walk, and the walking person is a Prime Minister of a country. The eye-catching logo allows people to say that JH is a 'paid' Prime Minister advertising a certain company, and this statement carried disrespecting connotation.

Another negative opinion was reflected in Picture 2e in Figure 4 showing JH was bending his knee that made his position is under the average level of other people and put him in an awkward and funny position[1]. He was examining and inspecting a boat or fishing rods which is ridiculous since there was nothing he could do or nothing relevant to him after doing it. This picture gives perfect support to Gawenda's comment that is "Just then, Howard and Janette, having inspected the tinnies and the fishing rods and the vacum-sealed packets of bait - for this we flew from Sydney to Brisbane? - headed for their car...."[1]

The last picture of $2 \mathrm{f}$ in Figure 4 emphasizes the overall emptiness of JH's campaign content. People's experience with election campaigns should bring them an expectation to see some powerful and inspiring speeches, well-argued debates, and satisfying answers on press conferences. However, as being portrayed by Picture $2 \mathrm{f}$, the prime ministry campaign was designed to be relaxing and easy for the candidate. The picture shows a friendly situation with the press people. JH was shaking hand instead of being given and answers difficult questions. Two men on the upper left corner were smiling, and another on the right is drinking. This gives the sense that the campaign atmosphere did not exist in this campaign trip. Nothing was meaningful and worth reporting during the campaign. 


\section{CONCLUSIONS}

The discussion on the results of analysis shows evidence that press or media photographs released by a big newspaper company are always carefully selected and designed in order to tell more messages to the readers. The photographs selection does not only serve as an aesthetic tool, but it functions as a discourse practice similar to verbal or written texts. In the case discussed in this study, the age differences, facial expressions, body gestures, and participants' activities that were frozen in the photographs are selected to sensibly strengthen the reporter's opinion as written in the feature report. In summary, the use of powerful pictures should help to build powerful news stories, features, and reports.

\section{REFERENCES}

[1] Michael Gawenda, "The last road trip," The Sydney Morning Herald, Sydney, p. 25, 10Nov-2007.

[2] H. Janks, "Critical Discourse Analysis as a Research Tool," Discourse Stud. Cult. Polit. Educ., vol. 18, no. 3, pp. 329-342, Dec. 1997.

[3] M. Gillespie and J. Toynbee, Analysing Media Texts (Volume 4). McGraw-Hill Education (UK), 2006.

[4] A. Bell and P. D. Garrett, Approaches to media discourse. Chichester: Wiley-Blackwell, 1998.

[5] G. Rose, Visual Methodologies: An Introduction to the Interpretation of Visual Materials. SAGE, 2007.

[6] J. Bignell, Media Semiotics: An Introduction, Second Edition. Manchester University Press, 2002. 